\title{
STUDY ON THE POSSIBLE EXISTENCE OF WATER ON THE MOON
}

\author{
ERICH ROBENS ${ }^{1}$ and STANISLAW HALAS ${ }^{2}$ \\ ${ }^{l}$ Institut für Anorganische Chemie und Analytische Chemie, \\ Duesbergweg 10-14, D-55099 Mainz, Germany \\ ${ }^{2}$ Mass Spectrometry Laboratory, Institute of Physics, Marie Curie-Skłodowska University, \\ Plac Marii Curie-Skłodowskiej 1, 20-031 Lublin, Poland
}

\begin{abstract}
Aim of an extensive research project is an analysis of surface properties of Moon's regolith covering and the assessment of the possible existence of usable water on the Moon. In the present paper a short historical survey on Moon's exploration and recent and planned missions is given. Recent recognitions are discussed on the basis of origin and history of the Moon and the import of water from other celestial bodies. Characteristic data and chemical composition of the Moon's surface are summarised with respect to possible water or ice preservation.

Experimental investigations have been made on three typical lunar regolith powder samples from the Apollo 11, 12 and 16 missions. The experiments include spectroscopic and thermal analysis, density measurements and sorptometry. In the present paper we give a survey on measuring methods applied and discuss some results. The measurements confirm results of investigations made with less sensitive equipment shortly after the missions. With regard to water occurrence we found that the regolith cover of the Moon surface is rather hydrophobic and can hardly store water as adsorbed layers.
\end{abstract}

Keywords: Moon, regolith, water, adsorption, surface area, porosity

\section{INTRODUCTION}

\section{General information}

Table 1 gives a survey (Wikipedia, 2009a) on actual missions aimed for mapping Moon's surface, its chemical and mineralogical composition and the gravitational field. For the planned manned stations water is to be transported from Earth. Some recent measurements indicate water deposits on Moon. It is the aim of the present study to clarify the possibility of the existence of useable water on the Moon.

The increasing interest in the Moon is astonishing, because as most scientists expected exploration of the Moon revealed a dusty celestial body without any valuable material. All-round astrophysical observations are not possible because the Moon is too big and on account of its large distance it is not ideal for the observation of Earth targets. The gravitational field is not zero. Moon's low gravitation would facilitate the start of spaceships but the advantage of easily available resources on Earth are

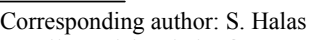

e-mail: stanislaw.halas@poczta.umcs.lublin.pl

ISSN 1897-1695 (online), 1733-8387 (print) @ 2009 GADAM Centre, Institute of Physics, Silesian University of Technology.

All rights reserved. prevailing. Considerable energy is required for a flight to the Moon, and flying time is remarkable.

At the moment the only material of interest is helium3 introduced by the solar wind which is not screened by a magnetic field as on Earth. Some ${ }^{3} \mathrm{He}$ is captured in regolith particles of the surface covering Helium-3 reacts by nuclear fusion to helium-4 whereby energy and protons are set free (Eqs. 1.2 and 1.3). The protons can be

Table 1. Recent and planned Moon missions.

\begin{tabular}{ll}
\hline $\begin{array}{l}\text { 28th September 2003- } \\
\text { 3th September 2006 }\end{array}$ & ESA Smart-1 \\
\hline 14.9 .2007 & Japan Kaguya in the orbit \\
\hline 26.10 .2007 & $\begin{array}{l}\text { Chinese satellite Chang'E-1 is in a } \\
100 \text { km polar orbit }\end{array}$ \\
\hline 22.10 .2008 & $\begin{array}{l}\text { Indian launch of Chandrayaan-1. Impact } \\
\text { probe }\end{array}$ \\
\hline 2009 & US sattlite "Lunar Reconnaissance \\
& Orbiter" \\
\hline 2011 & US sattlites "Grail" und "Ladee" \\
\hline 2015 & Russian sattelite "Lunar Glob" \\
& ESA "MoonNEXT " unmanned landing \\
& Satellites of England, Italy, South Korea \\
\hline 2020 & Chinese manned mission \\
\hline
\end{tabular}


used also for energy production. By the planned fusion of hydrogen to helium-4 many neutrons are set free (Eq. 1.1) which contaminate the reactor chamber and cause materials fatigue.

Fusion reactions proposed for energy production are as follows:

$$
\begin{aligned}
& \mathrm{D}+\mathrm{T} \rightarrow{ }^{4} \mathrm{He}+\mathrm{n}+2.8 \mathrm{pJ} \\
& \mathrm{D}+{ }^{3} \mathrm{He} \rightarrow{ }^{4} \mathrm{He}+\mathrm{p}+2.9 \mathrm{pJ} \\
& { }^{3} \mathrm{He}+{ }^{3} \mathrm{He} \rightarrow{ }^{4} \mathrm{He}+2 \mathrm{p}+2.1 \mathrm{pJ}
\end{aligned}
$$

\section{Moon's investigation}

A rough survey on Moon's exploration is compiled in Table 2. Moon's exploration started with the invention of the telescope 1608 (Watson, 2004) and its improvement and use for celestial observations by Galileo Galilei 1609 (Galilei, 1609). Later in the $17^{\text {th }}$ century, Giovanni Battista Riccioli (Riccioli, 1651) and Francesco Maria Grimaldi drew a map of the Moon and gave many craters the names they still have today. In 1835/36 Wilhelm Beer and Johann Heinrich Mädler published their four-volume Mappa Selenographica (Beer and Mädler, 1835/36) and the book Der Mond (Beer and Mädler, 1837), which firmly established the conclusion that on Moon there is neither water nor any appreciable atmosphere.

The first man-made object to land on the Moon was the Soviet Union's Luna 2 in 1959; the first photographs of the far side of the Moon were made by Luna 3 in the same year. The first manned mission Apollo 11 was on July 21, 1969 (Wikipedia, 2009b). Moon samples have been brought back to Earth by three Luna missions (Luna 16, 20, and 24) and the Apollo missions 11, 12, 14-17. In 1990 Japan visited the moon with the Hiten spacecraft, becoming the third country to orbit the Moon.

In 1994, the U.S. launched Clementine, a Joint Defense Department/NASA mission which completed the first multispectral map. Lunar Prospector confirmed the presence of excess hydrogen at the lunar poles, which some have speculated to be due to the presence of water
(Deiss, 2008), but recently valued as misinterpreted.

Though a considerable part of Moon exploration was inspired, developed and financed by military it has been demonstrated that mankind can manage large projects other than war. Our knowledge of the universe and in particular of our solar system was tremendously augmented and several odd hypothesis have been disproved (Hörbiger and Fauth, 1913; Fauth, 1913/1925; Nagel, 1991/2000; Koresh, 1922/2008).

\section{PHYSICAL AND CHEMICAL DATA OF THE MOON}

\section{Macroscopic data}

The Moon is comparable in size. Its diameter is about one quarter of that of Earth. We should recognise that the dwarf planet Pluto is smaller. However the Moon is a lightweight, 1/81 of the Earth mass, and therefore it is a real satellite and establishes not a double-planet system. A survey of important data is compiled in Table 3.

\section{Origin and evolution}

The inclination of the Moon's orbit makes it implausible that the Moon formed along with the Earth or was captured later. Recently, the giant impact hypothesis, first proposed in the 1940s by Reginald Aldworth Daly, has been considered the most viable. The Giant Impact hypothesis holds that the Moon formed from the ejecta resulting from a collision between a semi-molten Earth and a planet-like object the size of Mars (Wikipedia, 2009c; Hartmann and Davis, 1975). The material ejected from this impact would have gathered in orbit around Earth and formed the Moon. Through radiometric dating, it has been determined that the Moon's crust formed between 20 and 30 million years after that of Earth.

In the beginning the Moon was much closer to the Earth and strong tidal forces deformed the once molten sphere into an ellipsoid, with the major axis pointed towards Earth. The crust on the near side is much thinner $(\sim 70 \mathrm{~km})$ than on the far side $(\sim 150 \mathrm{~km})$. Especially during the late heavy bombardment, around 3800 to

Table 2. Timetable of exploration of the Moon.

\begin{tabular}{cll}
\hline 1609 & Invention of telescope & $\begin{array}{l}\text { Hans Lipperhey } \\
\text { Zacharias Janssen } \\
\text { Jacob Metius }\end{array}$ \\
\hline 1608 & Sidereus Nuncius & Galileo Galilei \\
\hline 1651 & Map of Moon & Giovanni Battista Riccioli Francesco Maria Grimaldi \\
\hline $1834-1836$ & Mappa Selenographica & Wilhelm Beer \\
& Der Mond & Johann Heinrich Mädler \\
\hline 1959 & $\begin{array}{c}\text { 1st landing on Moon: Luna 2 } \\
\text { Photographs of the far side: Luna 3 }\end{array}$ & \\
\hline 1969 & First people to land on the Moon: Apollo 11 & Neil Armstrong, Edwin Aldrin \\
\hline 1972 & Samples: Luna 16, 20, and 24 & Eugene Cernan \\
\hline 1976 & Samples: Apollo 11, 12, 14-17 & \\
\hline $1990-1993$ & Last man on Moon: Apollo 17 & \\
\hline 1994 & Last landing: Luna 24 & \\
\hline $1998-1999$ & Hiten spacecraft (Japan) & \\
\hline
\end{tabular}


Table 3. Characteristic data of the Moon (Wikipedia, 2009c).

\begin{tabular}{ll}
\hline Moon's age & $(4527 \pm 10) \times 10^{6}$ years \\
\hline Mean equator diameter & $3476 \mathrm{~km}$ \\
\hline Surface area & $37.9 \times 10^{6} \mathrm{~km}^{2}$ \\
\hline Mass & $\begin{array}{l}73.48 \times 10^{21} \mathrm{~kg}=1 / 81 \text { of Earth } \\
\text { mass }\end{array}$ \\
\hline Mean density & $3.345 \times 10^{3} \mathrm{~kg} \mathrm{~m}^{-3}$ \\
\hline Rotation period & $27 \mathrm{~d} 07 \mathrm{~h} 43.7 \mathrm{~min}$ \\
\hline Surface temperature & min. -160, mean -30, max. $+130^{\circ} \mathrm{C}$ \\
\hline Atmospheric pressure & $3 \times 10^{-10} \mathrm{~Pa}$ \\
\hline Average orbit from Earth & $384403 \mathrm{~km}$ \\
\hline $\begin{array}{l}\text { Time of an electromag- } \\
\text { netic signal to Earth }\end{array}$ & $1.3 \mathrm{~s}$ \\
\hline
\end{tabular}

4000 million years ago, many large meteorites were able to penetrate the thin crust of that near side but only very few could do so on the far side. Where the crust was perforated the hot lavas from the interior oozed out and spread over the surface, only to cool down later into the maria (Fig. 1).

The geological epochs of the Moon are defined based on the dating of various significant impact events in the Moon's history. The period of the late heavy bombardment is determined by analysis of craters and Moon rocks. Recently Moon's age was determined at $4527 \pm 10$ million years, which would imply that it was formed only 30 to 50 million years after the origin of the solar system (Hartmann and Davis, 1975).

\section{Selenography}

When observed with earth based telescopes, the moon can be seen to have some 30000 craters of a diameter of at least $1 \mathrm{~km}$, but close up observation from lunar orbit reveals a multitude of ever smaller craters (Josset and Foing, 2006). Most are hundreds of millions or billions of years old; the lack of atmosphere, weather and recent geological processes ensures that most of them remain permanently preserved.

The largest crater on the Moon, and indeed the largest known crater within the solar system, forms the South Pole-Aitken basin (Fig. 2). This crater is located on the far side, near the South Pole, and is some 2240 kilometres in diameter, and 13 kilometres in depth. Within that big crater many little craters are visible. Four mountainous regions on the rim of the $73 \mathrm{~km}$-wide Peary crater at the Moon's North Pole remain illuminated for the entire lunar day. These "mountains of eternal light" are possible due to the Moon's extremely small axial tilt, which also gives rise to permanent shadow at the bottoms of many polar craters.

The dark and relatively featureless, solidified basalt plains (maria) are relatively young areas on the Moon and cover about $20 \%$ of the surface (Fig. 1). The lightercoloured highlands, called terrae are mountainous and saturated with craters.

For billions of years, comets and meteoroids continuously bombarded the Moon. Rocks were shattered by these impacts. The comminute material together with the refractory materials of the celestial bullets contribute to Moon's regolith covering. Lunar soil is the subcentimeter

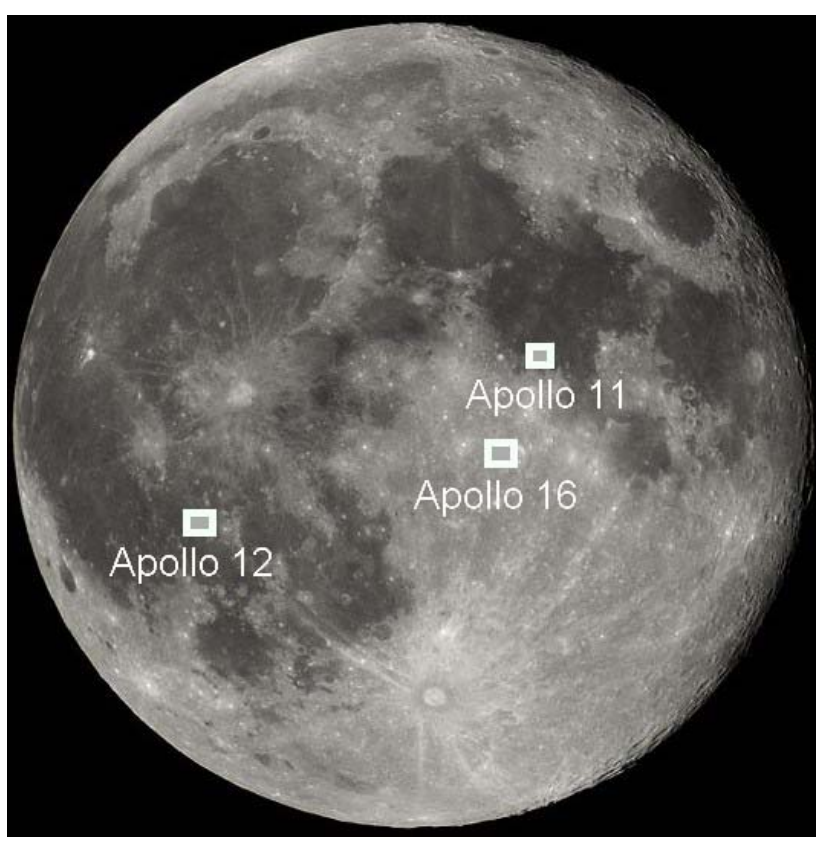

Fig. 1. Moon seen from Earth. The dark areas (about 20\% of the surface) are "maria", the rest "terrae" and the mountainous "highlands". The landing sites are inscribed of the missions from which the samples originate. UL1910a.jpg.

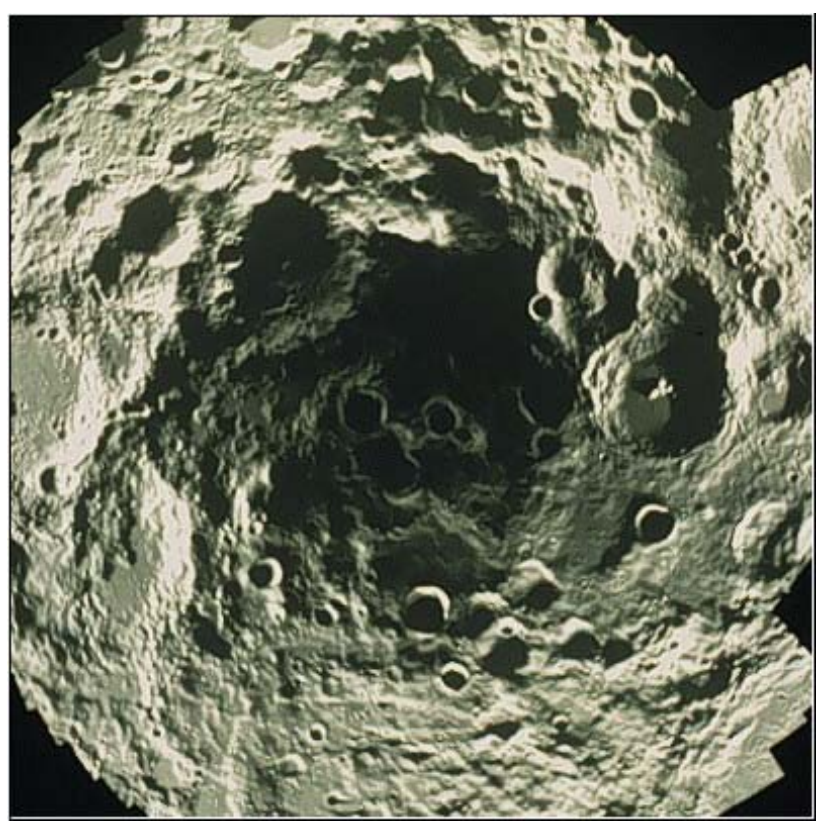

Fig. 2. South Pole - Aitken basin with smaller but deep craters inside. UL1901.jpg @ NASA.

fraction of the lunar regolith. The regolith above the crust varies from 3 to 5 metres in the maria to 10 to 20 metres in the highlands. Surface transport of dust, sand and stones occurs after an impact of celestial material, moonquake, evolving gas and thermal gas flow. Because gravitation is weak the moved material can be spread widely.

\section{Chemical composition}

More than 4.5 billion years ago, the surface of the Moon was a liquid magma ocean. It is believed that one 
component of lunar rocks, called creep (potassium, rare earth elements and phosphorus), represents the last chemical remnant of that magma ocean. Creep is actually a composite of "incompatible elements": those that cannot fit into a crystal structure and thus were left behind, floating to the surface of the magma. Creep is a convenient tracer, useful for reporting the story of the volcanic history of the lunar crust and chronicling the frequency of impacts by comets and other celestial bodies.

The lunar crust is composed of a variety of primary elements as determined by spectroscopy and summarised in Table 5. The overall composition of the Moon is believed to be similar to that of the upper zones of the Earth other excluding a depletion of volatile elements and of iron. Furthermore, material brought from outside is found at the surface, e.g. meteoritic iron. The environmental treatment of the minerals differed remarkably from that happening on Earth. At the solidified Moon crust there was always a strongly reducing environment (Allen and Todd, 2007; Papike et al., 1976). The surface has been exposed to high vacuum, unfiltered irradiation from the Sun, solar wind flux and particles from universe, dry milling by meteorites, and extreme variation of daily temperature (from -160 to $+130^{\circ} \mathrm{C}$ ). In contrast to Earth there is no water induced corrosion. So in particular the surfaces of minerals found on Moon differ from that on Earth.

In Moon's interior most probably an iron core exists with a temperature of $1600^{\circ} \mathrm{C}$. So indeed the Moon is a hot body.

\section{Presence of water}

The early Moon consisting of molten material included no water and hardly components for its synthesis. However, the solidified surface of the Moon was supplied with water when hit by spatial bodies. Cosmic dust particles are often covered with frozen volatiles, in particular water ice. Furthermore, it is believed that comets consist of blocks of refractory material, regolith and frozen volatiles, mostly water ice.

After hitting Moon's surface the ice of such a body will melt and vaporize when irradiated by the Sun and Moon's surface temperature increases up to $130^{\circ} \mathrm{C}$. The energy from sunlight splits much of this water into its constituent elements hydrogen and oxygen. Because the gravitational field is weak the gases escape fast into space.

Nevertheless, it has been hypothesized that significant traces of water remain on the Moon, some of the imported water is adsorbed. Weakly bound physisorbed water may comprise up to two molecular layers at the surface. Water condensed in pores is bound stronger. Some mineral surfaces hydratise and water is chemisorbed. If such a surface is hidden from solar radiation some of those stronger bound water may be hold for long time. Furthermore, remnants of water-rich comet impacts may be embedded unmelted in the permanently shadowed Pole craters.

First indications gave 1996 Clementine's radar data from a South Pole crater wall. Furthermore, at the Moon neutron radiation is observed as a reaction to the bombardment of cosmic radiation on the surface. Fast neutrons are slowed down by hydrogen and so the distribution of the neutron radiation gives some evidence for the presence of water distributed on the entire surface and concentrated in the polar regions as measured by Lunar Prospector (Deiss, 2008) in 1998. Estimates amount to about $6 \times 10^{6}$ up to $10^{9} \mathrm{~m}^{3}$ water in total. However, recent comparative investigations showed similar effects in the neutron spectrum caused by structured surfaces of dry stones (Spudis, 2006/7).

By the impact of a large object some of the ice which may be stored in a crater or below the regolith cover should be kicked up. Therefore after termination of its mission in 1999 the Lunar Prospector was navigated into a South Pole crater and 2006 Smart-1 into the Lacus Excellentiae 46.2 grad west and 34.4 grad south. No ice dust could be detected in this way. Neither observations with the Arecibo radio telescope into the Shackleton Crater nor photographs of the Japanese Kaguya satellite gave evidence for water.

In July 2008, traces of water were found in the interior of volcanic pearls from the Moon which had been brought to Earth by Apollo 15 (Saal et al., 2008).

\section{Atmosphere}

The Moon has a relatively insignificant and tenuous atmosphere. One source of this atmosphere is outgassing, the release of gases, for instance radon, which originate deep within the Moon's interior. Another important source of gases is the solar wind, which is briefly captured by the Moon's gravity.

\section{INVESTIGATION OF REGOLITH}

\section{Materials}

NASA stores $382 \mathrm{~kg}$ material gathered during the Apollo missions 1969-1976 (Allen and Todd, 2007). Three samples each of about $3 \mathrm{~g}$ we got for investigating the possibility of storing water (Table 4). Regolith was investigated exhaustively in the $1970^{\text {th }}$ (Heiken et al., 1991), but meanwhile instruments and methods had been improved and there are several new methods. Furthermore we have today a better knowledge of surface properties and of the binding mechanisms at surfaces. Therefore we repeated in addition chemical and mineralogical analysis. Whilst some of the results are published elsewhere (Robens et al., 2007; Robens et al., 2008a, Dąbrowski et al.,

Table 4. Regolith samples.

\begin{tabular}{lllcc}
\hline Sample No & Mission & Origin & Colour & Density $\mathbf{( g ~ \mathbf { ~ m } ^ { - 3 } )}$ \\
\hline 10084.2000 & Apollo 11 & Mare & Dark gray & $3.10 \pm 0.01$ \\
\hline 12001.922 & Apollo 12 & Mare & Light gray, few white particles & $3.10 \pm 0.01$ \\
\hline 64501.228 & Apollo 16 & Highland & Light gray & $2.79 \pm 0.01$ \\
\hline
\end{tabular}


2008; Robens et al., 2008b), other investigations are still in progress. In the present paper we present a summary of element analysis, thermal analysis and sorptometry.

\section{Methods}

\section{Microscopy}

All samples were inspected by means of conventional light microscopes of different type.

The fine-grained textures of the lunar soils were studied with different types of Scanning Electron Microscope (SEM): a field-emission SEM (JEOL JSM-6300F) at the University of Münster (ICEM, Interdisciplinary Center for Electron Microscopy and Microanalysis), an upgraded Tesla SEM at Maria Curie-Skłodowska University, Lublin, a Hitachi S3500 N SEM at Warsaw University of Technology and a FEI Quanta 200 FEG SEM at AGHUniversity of Science and Technology, Cracov. Various preparation methods had been applied: direct observation, sputtering of the sample with an ultrathin gold/palladium film and by means of carbon shadowing. Backscattered electron (BSE) and scattered electron (SE) observations were performed using scanning electron microscope equipped with EDS detector.

All samples were investigated using an atomic force microscope (NanoScope III type, Digital Instruments, USA), a very high-resolution type of scanning probe microscope, which demonstrated resolution of fractions of a nanometer far below the resolution of SEM.

\section{Spectroscopy}

With Raman spectroscopy a laser produced monochromatic light illuminates the sample. A very small proportion of the incident light $\left(\sim 10^{-6}\right)$ is scattered at new frequencies being shifted up or down relative to the basic frequency. This wavelength difference yields the socalled Raman shift which allows phase analysis and elucidation of crystal structures. We used inVia Reflex Raman spectrometer (Renishaw plc, UK). This instrument comprises an optical microscope coupled to a singlegrating spectrograph fitted with a charge-coupled camera detector (CCD). Such coupling allows to identifying the spot of the investigated sample and making it visible by the means of false colours to distinguish between parts of different chemical composition. The respective Raman spectrum can be evaluated quantitatively and related to each spot of the image.

An identification of elements composing the lunar samples was based on XRF method. The ED-XRF spectrometer model 1510 (Canberra Packard, USA) equipped with sets of radioactive sources was used for measurements. Small samples of lunar regolith of $150 \mathrm{mg}$ in size were prepared as very thin pellets with surface density of $0.0478 \mathrm{~g} \mathrm{~cm}^{-2}$. The excitation source was Fe-55 for light elements (from $\mathrm{Al}$ to $\mathrm{Ti}$ ) or $\mathrm{Cd}-109$ for heavier ones (from Ti to Mo). The mass analysis was carried out using the standardless method.

For elemental analysis we applied X-ray fluorescence (XRF) and X-ray diffraction analysis (XRD). By means of X-ray diffraction XRD diffractogram are obtained and compared with library reference diffractograms in order to identify the crystal structure of the minerals. In addition EDX, ICP-MS and other analytical methods had been applied. X-ray powder diffraction pattern were measured with HZG-4 Diffractometer (Carl Zeiss, Germany) using $\mathrm{Cu} \mathrm{K} \alpha$ radiation.

Furthermore Fourier-transform infrared/photoacoustic measurements were made. With infrared spectroscopy a sample's absorbance is analyzed in its infrared spectrum (IR) with wavelength range of 25-2.5 $\mathrm{nm}$. That absorbance spectrum is then analyzed by means of the Fourier transform method. In conventional transmission spectroscopy the measurement of absorption is transferred to a measurement of the radiation transmitted through the sample. In photoacoustic spectroscopy (PAS) the absorption radiation is determined directly via the heat released (Ryczkowski, 2007; Haskin et al., 1997). That short-time release heat produces pressure waves in the surrounding gas, and that sound is detected by means of a microphone (FT-IR/PAS). The FT-IR/PAS were recorded by means of a Bio-Rad Excalibur 3000MX spectrometer equipped with a photoacoustic detector MTEC 300 (with helium atmosphere in the detector) covering the $4000-400 \mathrm{~cm}^{-1}$ range at a resolution of $4 \mathrm{~cm}^{-1}$ and maximum source aperture.

\section{Density}

The mean density of the powders was determined by means of helium displacement within a calibrated vessel (Heiken et al., 1991, Dąbrowski et al., 2003) at $20^{\circ} \mathrm{C}$. We used a PYCNOMATIC ATC instrument of Thermo Electron S.p.A., Milano, Italy.

\section{Thermogravimetry, differential thermal analysis and TPRO}

Thermogravimetry TGA and differential thermal analysis DTA studies were made in order to clear whether lunar material is able to ad- and absorb significant amounts of water and to retain water molecules. We used a Setsys 16/18 apparatus (Setaram, France) (Iwan et al., 2007). Samples (5-8 mg) were heated at temperatures of $30-900^{\circ} \mathrm{C}$.

The Temperature Programmed Reduction and Oxidation is a thermoanalytical technique for characterising chemical interactions between solids and reacting gases. Studies were conducted on Altamira AMI-1 system (Zeton Altamira) equipped with thermal conductivity detector (TCD) and coupled with mass spectrometer HAL 211RC (Hiden Analytical, U.K.). High purity $\mathrm{He}$ and $\mathrm{Ar}$ and gaseous mixtures of $6.21 \% \mathrm{H}_{2} / \mathrm{Ar}$ and $5 \% \mathrm{O}_{2} / \mathrm{He}$ were used in the experiments.

\section{Gas adsorption}

Low temperature krypton adsorption isotherms were measured stepwise using a volumetric/manometric apparatus SORPTOMATIC of Thermo Electron S.p.A., Milano, Italy. Low temperature nitrogen adsorption isotherms were measured using a volumetric/manometric Quantachrome Autosorb-1CMS apparatus (U.S.A.). Sorption of water and some organic vapours was measured at ambient temperature by means of gravimetric 
DVS 1/ Advantage Apparatus of Surface Measurement Systems, Ltd., Wembley, Middlesex U.K. The apparatus encompasses a Cahn microbalance with a maximum load of $1.5 \mathrm{~g}$. Water vapour pressure is adjusted and varied by means of a flow of nitrogen carrier gas saturated with water vapour.

All adsorption isotherms were measured stepwise. From each isotherm the specific surface areas was calculated using the two-parameter equation of Brunauer, Emmett and Teller (Brunauer et al., 1938). Furthermore the pore size distribution was established using the methods of Barret, Joyner and Halenda (BJH) (Barret et al., 1951) and Dollimore and Heal (DH) (Dollimore and Heal, 1964) and the specific mesopore volume $V_{B J H}$ was determined.

\section{RESULTS AND DISCUSSION}

In accordance with literature reports our studies have shown that five basic particle types make up the lunar soils: mineral fragments, pristine crystalline rock fragments, breccia fragments, glasses of various kinds, and the unique lunar structured particles called agglutinates (Heiken et al., 1991). The mineral and chemical composition of the lunar soils depends on the mission landing sites (Stöffler et al., 1985). Apollo 11 and Apollo 12 landed well inside mare basalt regions, and consequently, soil samples from these sites have abundant mare-derived basaltic rock clasts and mafic minerals like olivine and pyroxene. On the other hand Apollo 16 landed in highland regions. Soils from this mission contain abundant highland-derived components, e.g. lithic fragments of anorthositic rocks, breccias, and anorthitic feldspar.

Scanning electron microscopy show abundant clastic grains with pores and roughly cleaved surface for all samples (Figs 3-5). Typically also impact molten spherules of various sizes are included. In such spheres recently traces of water had been found (Saal et al., 2008). Atomic force microscopy images reveal a rather flat and hardly structured surface without pores of nanometer scale (Fig. 6). With Secondary Ion Microscopy characteristic differences were found between the samples from maria and from highlands.

In Table 5 results of X-ray fluorescence measurements are compared with values published by NASA.

The density values for lunar soils reported in literature (Heiken et al., 1991) range from 2.3 to $>3.2 \mathrm{~g} \mathrm{~cm}^{-3}$ giving a recommended mean value of $3.1 \mathrm{~g} \mathrm{~cm}^{-3}$. The mean values of our measurements (Table 4) are identical or close to that value.

We measured krypton and nitrogen adsorption isotherms at $77.1 \mathrm{~K}$ using the volumetric/manometric method and calculated the specific surface area by means of the 2-parameter BET equation. Very low surface areas resulted, in the mean of about $0.5 \mathrm{~m}^{2} \mathrm{~g}^{-1}$, in accordance with results reported in the literature and as seen under the atomic force microscope. It seems that by heat treatment (degassing at $200^{\circ} \mathrm{C}$ ) the surface is damaged resulting in three times higher values of the nitrogen isotherms. Adsorption and desorption of gases and vapours proceeds rapidly as is typical for material without pores of nanometer size range. The Krypton isotherms (Fig. 7) show

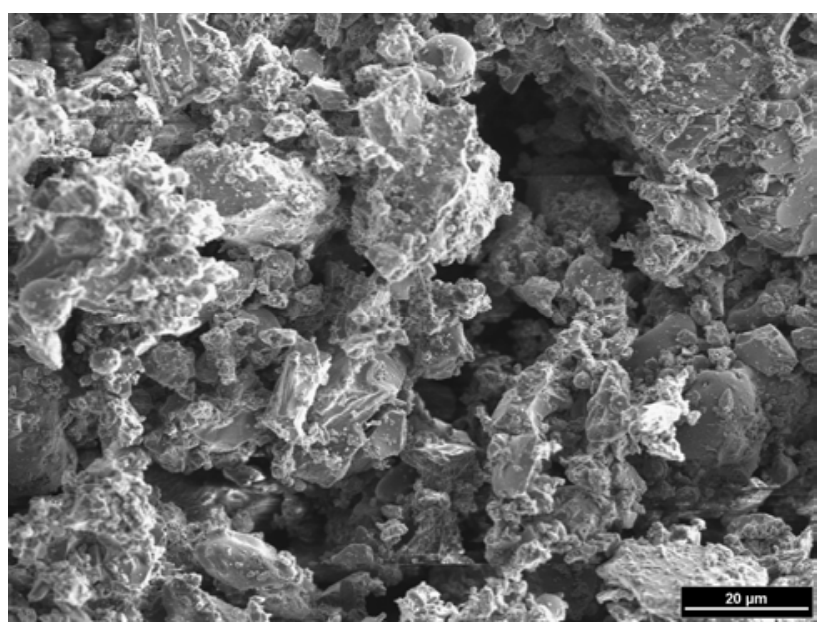

Fig. 3. SEM picture of regolith sample. 10084.2000 of the Apollo11 mission from inside of a mare basalt region. No 10084-19 @ Universität Münster.

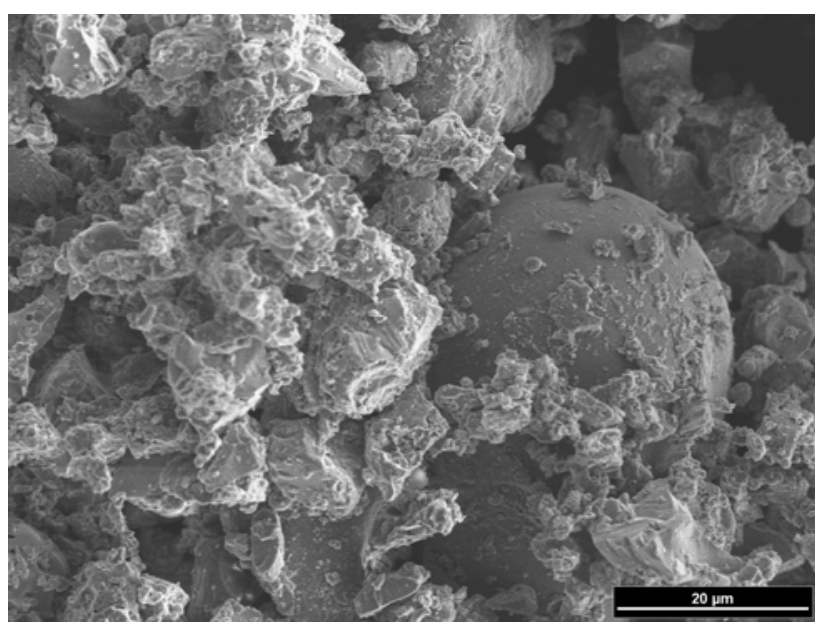

Fig. 4. SEM picture of regolith sample. 64501.228 of the Apollo12 mission from highland region No 12001-06 @ Universität Münster.

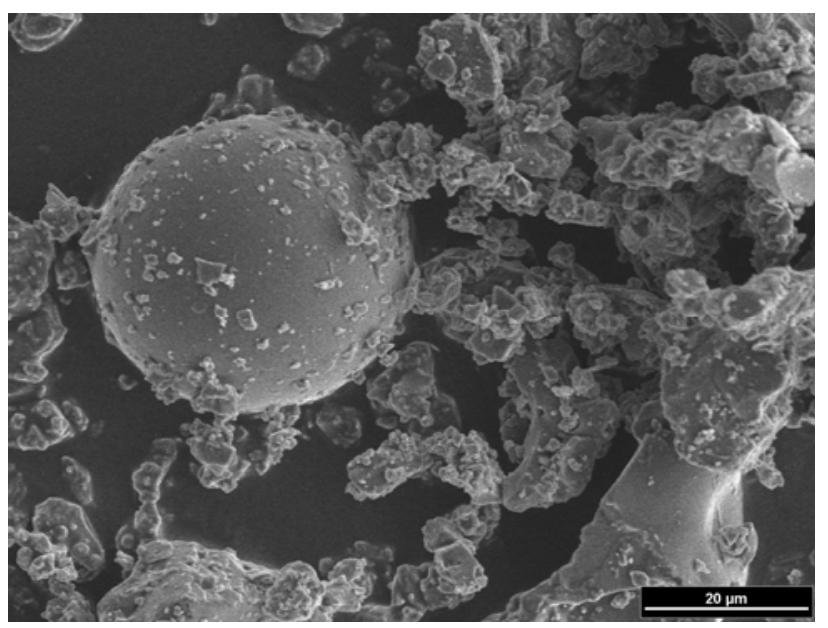

Fig. 5. SEM picture of regolith sample. 64501.228 of the Apollo16 mission from highland region No 64501-15 @ Universität Münster. 

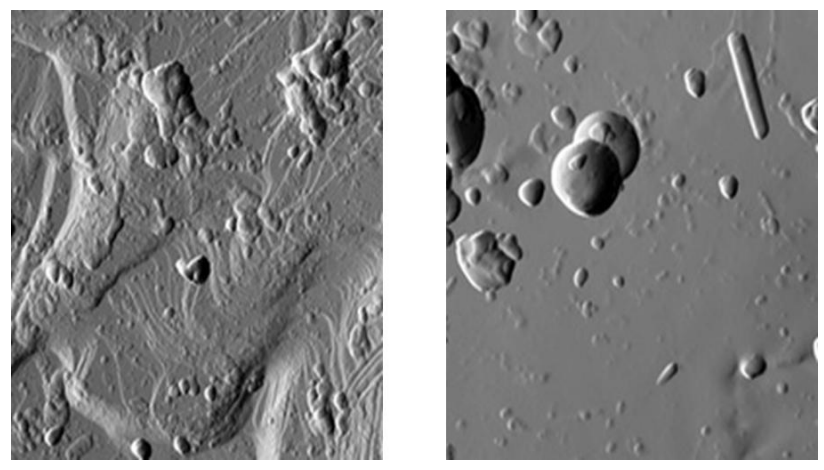

Fig. 6. Atomic force micrographs of the Apollo 12 sample from mare at $2 \mu \mathrm{m}$ (left image) and $3 \mu \mathrm{m}$ (right image) scan sizes. Data obtained in tapping mode in air. UL1904.jpg @ UMCS Lublin.

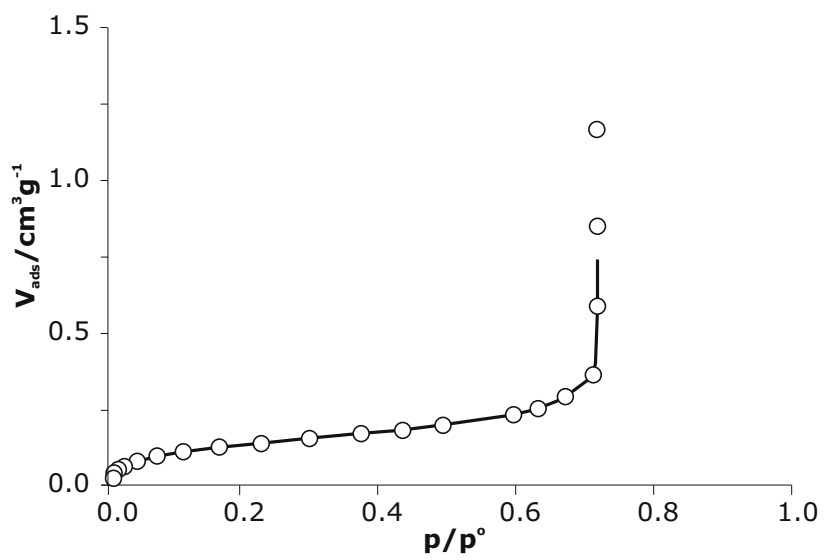

Fig. 7. Krypton adsorption isotherm at $77.1 \mathrm{~K}$ of lunar regolith sample 64501.228 from highland. The ordinate represents the adsorbed gas volume at S.T.P. divided by the mass of the degassed sample. The abscissa is the measured pressure above the capillary (diameter $10 \mathrm{~mm}$ ) of the sample vessel related to the saturation pressure of 233 Pa. UL1564.bmp @ P POROTEC, Hofheim.

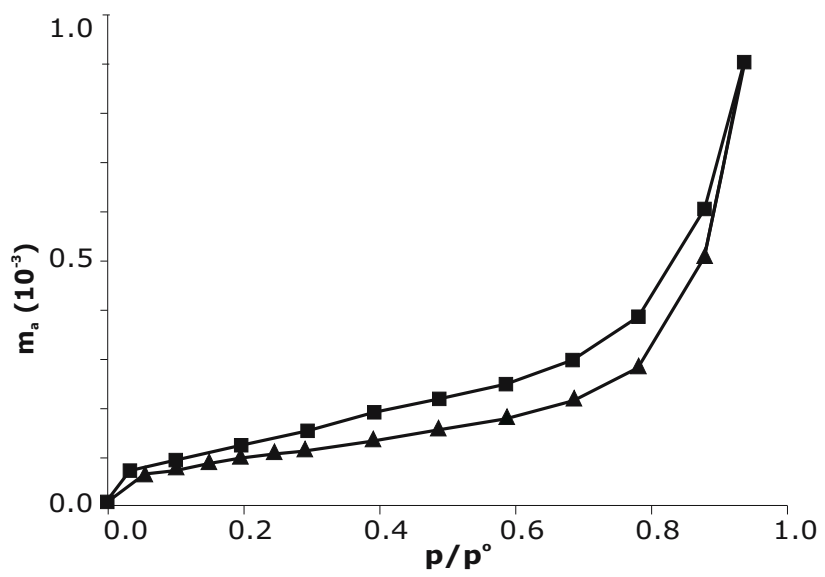

Fig. 8. Water adsorption and desorption isotherm at $24.9^{\circ} \mathrm{C}$ of lunar regolith sample 64501.228 from highland. $\boldsymbol{\Delta}$ adsorption, - desorption. $m_{a}$ adsorbed water mass related to unit sample mass, $p / p^{\circ}$ water vapour pressure related to saturation pressure (relative humidity). UL1842.jpg @ P POROTEC, Hofheim.

the typical profile of adsorption of a neutral gas at a smooth and surface: steep increase already at low pressure to a low level due to monolayer covering followed by slow increase in a wide pressure range with slow for-
Table 5. XRF results of element abundance in the regolith samples (Robens et al., 2008b) and mean composition of Moon's crust (Wikipedia, 2009).

\begin{tabular}{|c|c|c|c|c|}
\hline Element & $\begin{array}{l}\text { Apollo } 11 \\
10084.2000\end{array}$ & $\begin{array}{l}\text { Apollo } 12 \\
12001.922\end{array}$ & $\begin{array}{l}\text { Apollo } 16 \\
64501.228\end{array}$ & $\begin{array}{c}\text { Mean crust } \\
\text { composition } \\
(\%)\end{array}$ \\
\hline $\mathrm{H}$ & & & & 0.005 \\
\hline $\mathrm{He}$ & & & & 0.002 \\
\hline$C$ & & & & 0.01 \\
\hline $\mathrm{N}$ & & & & 0.01 \\
\hline 0 & & & & 43 \\
\hline $\mathrm{Na}$ & $0.18 \%$ & $0.29 \%$ & $0.21 \%$ & 0.3 \\
\hline $\mathrm{Mg}$ & $4.40 \%$ & $4.00 \%$ & $2.00 \%$ & 5 \\
\hline Al & $9.51 \%$ & $9.23 \%$ & $15.13 \%$ & 10 \\
\hline$P$ & & & & 0.05 \\
\hline s & & & & 0.1 \\
\hline $\mathrm{Si}$ & $19.12 \%$ & $22.04 \%$ & $19.10 \%$ & 21 \\
\hline $\mathrm{K}$ & $0.21 \%$ & $0.22 \%$ & $<787$ ppm & 0.1 \\
\hline $\mathrm{Ca}$ & $9.85 \%$ & $8.95 \%$ & $11.84 \%$ & 9 \\
\hline $\mathrm{Ti}$ & $5.11 \%$ & $2.12 \%$ & $0.31 \%$ & 2 \\
\hline $\mathrm{Cr}$ & $0.21 \%$ & $0.29 \%$ & 731ppm & 0.2 \\
\hline $\mathrm{Mn}$ & $0.14 \%$ & $0.16 \%$ & 445ppm & 0.1 \\
\hline $\mathrm{Fe}$ & $10.55 \%$ & $10.91 \%$ & $2.83 \%$ & 9 \\
\hline $\mathrm{Ni}$ & 214ppm & $137 \mathrm{ppm}$ & $211 p p m$ & 0.6 \\
\hline $\mathrm{Cu}$ & - & - & $36 \mathrm{ppm}$ & \\
\hline $\mathrm{Zn}$ & 42ppm & - & 44ppm & \\
\hline $\mathrm{Sr}$ & 138ppm & 120ppm & $149 \mathrm{ppm}$ & \\
\hline$Y$ & 82ppm & $94 \mathrm{ppm}$ & $29 \mathrm{ppm}$ & \\
\hline $\mathrm{Zr}$ & $\begin{array}{c}247 p p \\
\mathrm{~m}\end{array}$ & 404ppm & 132ppm & \\
\hline $\mathrm{Nb}$ & $11 p p m$ & 23ppm & 8ppm & \\
\hline $\mathrm{Pb}$ & - & - & $39 p p m$ & \\
\hline
\end{tabular}

mation of a second and a third layer, then again a steep increase due to filling of pores in the micrometer range. The isotherms are strongly reversible.

Water vapour adsorption we measured with a microbalance at ambient temperature as before other researchers. That method is more sophisticated and more sensitive. The isotherm (Fig. 8) shows a small and nearly linear slope that is typical for adsorption at almost hydrophobic surfaces. A hysteresis loop may be due to hydratisation processes.

$\mathrm{n}$-heptane and n-octane ad- and desorption at ambient temperature proceeded rapidly, which indicates the absence of pores with entrance width of few molecular diameters. In addition fast desorption indicates weak binding. The resulting isotherms have no hysteresis between adsorption and desorption branch. This suggests the absence of pores having nanometer widths. The specific surface area determined with those adsorptives is lower than that determined with krypton. This is reasonable because the molecular diameters of $n$-hydrocarbons are of about $0.6 \mathrm{~nm}$ and are larger than that of krypton (diameter $0.36 \mathrm{~nm}$ ). They cannot penetrate into the small pores which are accessible to krypton.

Also results of thermal analysis show that lunar material is not hygroscopic. In contact with the atmosphere quantities adsorbed are below the detection limit. Above $350^{\circ} \mathrm{C}$ by TG in air all lunar samples undergo slow oxidation processes (Iwan et al., 2007). Temperature programmed reduction and oxidation showed only low reac- 
tivity with hydrogen and oxygen at temperatures up to $900^{\circ} \mathrm{C}$.

\section{CONCLUSIONS}

With modern instrumentation we obtained more detailed information of the chemical and mineralogical composition and the surface properties of the regolith samples. In general we confirmed results reported in the literature (Fuller et al., 1979; Robens et al., 1980; Keller et al., 2002). The regolith sample show only low reactivity with hydrogen and oxygen even at high temperatures. Adsorbed gases, water vapour and organic vapours are completely released in high vacuum. No significant differences in sorption properties have been detected for samples of different origin (mare or highland).

Water-ice is imported to the Moon by comets and cosmic dust particles. Lunar regolith can hardly store water due to low specific surface area, little nano-porosity and an almost hydrophobic character. Structures like permafrost as observed on Earth (Anderson and Morgenstern, 1973) and assumed on Mars (Möhlmann, 2003) cannot be expected on Moon. Until now there is no evidence for usable water.

\section{ACKNOWLEDGENMENTS}

This paper is dedicated to Dr. Gerd Sandstede on the occasion of his $80^{\text {th }}$ birthday.

The samples had been kindly provided by the NASA Lunar sample curator, Dr. Gary Lofgren, Houston, Texas, USA.

The authors are deeply thankful to the many colleagues which had been engaged in the investigations:

Addi Bischoff, Institute for Planetology, University of Münster, Germany.

Andreas Schreiber, POROTEC GmbH, Hofheim, Germany.

Klaus K. Unger, Johannes Gutenberg-Universität, Mainz, Germany.

Andrzej Dąbrowski, Ewaryst Mendyk, Jacek Goworek, Krzysztof Skrzypiec, Marek Drewniak, Magdalena Dumańska-Słowik, Wojciech Gac, Ryszard Dobrowolski, Sylwia Pasieczna-Patkowska, Mariola Iwan, Janusz Ryczkowski, Zofia Rzączyńska, Maria Curie-Skłodowska University, Lublin, Poland.

Milosh Huber, AGH-University of Science and Technology, Kraków, Poland.

Krzysztof J. Kurzydłowski, Tomasz Płociński, Warsaw University of Technology, Warszawa, Poland.

Janusz W. Sobczak, Polish Academy of Sciences. Warszawa, Poland

\section{REFERENCES}

Allen C and Todd NS, 2007. Astromaterials curation - Rocks and soils from the Moon. http://curator.jsc.nasa.gov/lunar/index.cfm, NASA.

Anderson DM and Morgenstern NR, 1973. Physics, Chemistry and Mechanics of Frozen Ground, a Review. Proceedings of the 2nd Int. Permafrost Conf. National Academy of Science, Washington, DC: $257-288$.

Barret EP, Joyner LG and Halenda PH, 1951. The determination of pore volume and area distribution in porous substances. I. Computation from nitrogen isotherms. Journal of American Chemical Society 73: $373-380$

Beer W and Mädler JH, 1835/36. Mappa Selenographica totam lunae hemisphceram visibilem complectens observata. Berlin, Schropp \& Soc. (in German).

Beer W and Mädler JH, 1837. Der Mond nach seinen kosmischen und individuellen Verhältnissen oder Allgemeine vergleichende Selenographie. Berlin: 432 pp (in German).

Brunauer S, Emmett PH and Teller E, 1938. Adsorption of gases in multimolecular layers. Journal of American Chemical Society 60: 309-319.

Dąbrowski A, Robens E, Klobes P, Meyer K and Podkoscielny P, 2003. Standardization of methods for characterizing the surface geometry of solids. Particle \& Particle Systems Characterization 20: 311-322.

Dąbrowski A, Iwan M, Mendyk E, Robens E and Rzączyńska Z, 2008. Investigation of surface properties of lunar regolith - Part III. Journal of Thermal Analysis and Calorymetry 94: 633-639.

Deiss B, 2008. Wassereis auf dem Mond. AstroLink.de. http://www.planetenkunde.de/p012/p01205/index.htm.

Dollimore D and Heal GR, 1964. An Improved Method for the Calculation of Pore Size Distribution from Adsorption Data. Journal of Applied Chemistry 14: 109.

Fauth P, 1913/1925. Hörbigers Glazialkosmogonie, Hermann Kayser, Kaiserslautern/Leipzig (in German).

Fuller EL Jr., Poulis JA, Czanderna AW and Robens E, 1979. Volumetric and gravimetric methods of determining monolayer capacities. Thermochimica Acta 29: 315-318.

Galilei G, 1609. Sidereus Nuncius. Venezia, Thomam Baglionum.

Hartmann WK and Davis DR, 1975. Satellite-sized planetesimals and lunar origin. Icarus 24: 504-515.

Haskin LA, Wang A, Rockow KM, Jolliff BL, Korotev RL and Viskupic KM, 1997. Raman spectroscopy for mineral identification and quantification for in situ planetary surface analysis: A point count method. Journal of Geophysical Research 102 (E8): 19293-19306.

Heiken GH, Vaniman DT and French BM (Eds.), 1991. Lunar Sourcebook. Cambridge, Cambride University Press: 736 pp.

Hörbiger H and Fauth P, 1913. Glazialkosmogonie. Kaiserslautern, Kayser (in German).

Iwan M, Rzączyńska Z, Mendyk E, Dąbrowski A and Robens E, 2007. In IX Krajowe Seminarium im. Prof. Stanislawa Bretsznajdera Seminary on Thermal Analysis. Instytut Chemii Politechniki Warszawskiej, Mechaniki i Petrochemii w Plocku, Płock: 164-168 (in Polish).

Josset J-L and Foing BH, 2006. SPACE-X Space Exploration Institute and ESA SMART-1 Project. http://www.esa.int/esaSC/ SEMGBM9ATME index 0. html

Keller JU, Robens E and du Fresne von Hohenesche C, 2002. Thermogravimetric and Sorption Measurement Techniques/ Instruments. In: Rodríguez-Reinoso F, McEnaney B, Rouquerol J and Unger KK (Eds.) Characterization of Porous Solids VI.(6). Amsterdam, Elsevier: 387-394.

Koresh (Koresh $=$ pseudonym of Teed, Cyrus Reed) 1922/2008. The Cellular Cosmogony, INDYPUBLISH.COM.

Möhlmann D, 2003. Unfrozen subsurface water on Mars: presence and implications. Internal Journal of Astrobiology 2: 213-216.

Nagel B, 1991/2000. Die Welteislehre - Ihre Geschichte und ihre Rolle im "Dritten Reich", GNT-Verlag, Berlin/Diepholz (in German).

Papike JJ, Hodges FN, Bence AE, Cameroni M and Rhodes JM, 1976. Mare basalts - Crystal chemistry, mineralogy, and petrology. Review of Geophysics and Space Physics 14: 475-540.

Riccioli GB, 1651 Almagestum novum astronomiam veterem novamque complectens observationibus aliorum et propriis novisque theorematibus, problematibus ac tabulis promotam, Bologna: 204pp.

Robens E, Czanderna AW and Poulis JA, 1980. Surface Area and Pore Size Determination on Finely Divided or Porous Substances by Adsorption Measurements: Comparison of Volumetric and Gravimetric Methods. Powder Metallurgy International 12: 201-203.

Robens E, Bischoff A, Schreiber A, Dąbrowski A and Unger KK, 2007. Investigation of surface properties of lunar regolith - Part I. Applied Surface Science 253: 5709-5714.

Robens E, Bischoff A, Schreiber A and Unger KK, 2008a. Investigation of surface properties of lunar regolith - Part II. Journal of Thermal Analysis and Calorimetry 94: 627-631.

Robens E, Dąbrowski A, Chibowski S, Dobrowolski R, Drewniak M, Dumańska-Słowik M, Gac W, Goworek J, Huber M, Iwan M, Kurzydłoski KJ, Mendyk E, Pasieczna-Patkowska S, Płociński T, 
Ryczkowski J, Rzączyńska Z, Skrzypiec K and Sobczak JW, $2008 \mathrm{~b}$. Investigation of surface properties of lunar regolith - Part IV. Annales Universitatis Mariae Curie-Skłodowska Lublin, Polonia, Sectio AA Chemia LXIII: 144-168.

Ryczkowski J, 2007. Application of infrared photoacoustic spectroscopy in catalysis. Catalysis Today 124: 11-20.

Saal AE, Hauri EH, Cascio ML, Van Orman JA, Rutherford MC and Cooper RF, 2008. Volatile content of lunar volcanic glasses and the presence of water in the Moon's interior. Nature 454: 192-195.

Spudis P, 2006/7. Ice on the Moon. The Space Review 06/11 and 07/4.

Stöffler D, Bischoff A, Borchardt R, Burghele A, Deutsch A, Jessberger EK, Ostertag R, Palme H, Spettel B, Reimold WU, Wacker R and
Wänke H, 1985. Proceedings of the 15th Lunar Planet. Sci. Conference. Journal of Geophysical Research C449-C506.

Watson F, 2004. Stargazer: The Life and Times of the Telescope. Sydney, Cambridge: Allen \& Unwin, Da Capo Press: 342pp.

[Wikipedia] Wikipedia, the free encyclopedia, 2009a. WEB site: $<$ http://en.wikipedia.org/wiki/Apollo_moon_landing_hoax_accusa tions/>. Accessed 2009 August 15.

[Wikipedia] Wikipedia, the free encyclopedia, 2009b. WEB site: $<$ http://en.wikipedia.org/wiki/Giant impact hypothesis/>. Accessed 2009 August 15.

[Wikipedia] Wikipedia, the free encyclopedia, 2009c. WEB site: $<\mathrm{http}$ ///en.wikipedia.org/wiki/Moon/>. Accessed 2008 August 15. 